\title{
Influence of Metallic Copper Vapors on the Chemical Composition of a Mixture of Air and Water Vapor Thermal Plasmas in the Temperature Range $1000 \mathrm{~K}$ to $20000 \mathrm{~K}$
}

\author{
Kohio Nièssan*, Kagoné Abdoul Karim, Yaguibou Wêpari Charles, Koalaga Zacharie, \\ Zougmoré François
}

Laboratory of Materials and Environment (LAME), Department of Physics, University Joseph KI-ZERBO, Ouagadougou, Burkina Faso

Email address:

kohioniessan@hotmail.fr (K. Nièssan)

*Corresponding author

\section{To cite this article:}

Kohio Nièssan, Kagoné Abdoul Karim, Yaguibou Wêpari Charles, Koalaga Zacharie, Zougmoré François. Influence of Metallic Copper Vapors on the Chemical Composition of a Mixture of Air and Water Vapor Thermal Plasmas in the Temperature Range $1000 \mathrm{~K}$ to $20000 \mathrm{~K}$. American Journal of Nano Research and Applications. Vol. 8, No. 3, 2020, pp. 50-57. doi: 10.11648/j.nano.20200803.13

Received: August 18, 2020; Accepted: September 18, 2020; Published: October 12, 2020

\begin{abstract}
This paper concern the calculation of equilibrium composition of plasma mixture Air-Water vapor and copper vapor in temperatures range $1000 \mathrm{~K}$ to $20000 \mathrm{~K}$. The plasma is suposed to be in local thermodynamic equilibrium. We used Gibbs free energy minimization method to access the different numerical densities of chemical species as a function of temperature. This data are very important to calculate thermodynamic properties, transport coefficients and modeling electrical arc in circuit breakers. The result shows that the influence of metallic copper vapor is important on equilibrium composition of plasma. In particular the densities of electron in the plasma increase with the percentage of copper vapor for the temperature inferior to $17000 \mathrm{~K}$. The increasing of electron densities increase electrical conductivity of plasma and limit the performance of circuit breakers. Also the electrical neutrality is made mainly between electron $\left(\mathrm{e}^{-}\right)$and $\mathrm{Cu}^{+}$in low temperature $(\mathrm{T}<12000 \mathrm{~K})$. We are studying in particular the evolution of the densities of the main chemical species created in this plasma as a function of pressure. We choose four values of pressure (1 atm, $5 \mathrm{~atm}, 10 \mathrm{~atm}$ and $15 \mathrm{~atm})$. The results obtained shows an increasing of chemical densities with the pressure in the mixture in conformity at Dalton's Law. the increasing of the pressure in the plasma retard chemical reactions because it disadvantages the dislocations that constitute dissociation and ionization reactions in the plasma.
\end{abstract}

Keywords: Plasma, Equilibrium Composition, Gibbs Free Energy, Copper, Electrical Neutrality

\section{Introduction}

Air and compressed air are used in low and medium voltage circuit breakers for breaking the electrical current through the electric arc. In some regions of high humidity the air contains a certain proportion of water vapor depending on climatic conditions $[1,2]$. This water vapor can modify the properties of the plasma created during the interruption of the electric current. In addition, the evaporation of copper contacts in the circuit breaker can also have a significant influence on the chemical composition and the properties of the plasma created in this circuit breaker [3, 4]. Our previous studies have shown the role played by water vapor on the equilibrium composition of an air plasma $[2,5,6]$. The objective of this present study is to show the influence of the metallic copper vapor resulting from the evaporation of the contacts of the copper in circuit breaker on the equilibrium composition of a plasma formed by air and water vapor mixture. In our study, the air is constituted of $80 \%$ nitrogen $\left(\mathrm{N}_{2}\right)$ and $20 \%$ dioxygen $\left(\mathrm{O}_{2}\right)$; the other components of the air are neglected. Plasma is a mixture of air, water vapor and copper vapor; so we have plasmas of type $\mathrm{NxOyHzCu}_{t}$; with $\mathrm{x}, \mathrm{y}, \mathrm{z}$ and $\mathrm{t}$ are fractional or integer values depending on the initial proportions of the mixture. We used Gibbs free energy minimization method to access the different numerical densities of chemical species in function of temperature [713]. These data are important for accessing the transport coefficients and the thermodynamic properties of these types 
of plasmas. These data are also important for modeling electric arcs and hydrodynamic studies using these same types of plasmas. The study is done in the temperature range from $1000 \mathrm{~K}$ to $20000 \mathrm{~K}$ and for pressures $\mathrm{P}=1 \mathrm{~atm}, \mathrm{P}=5$ atm, $\mathrm{P}=10 \mathrm{~atm}$ and $\mathrm{P}=15 \mathrm{~atm}$.

\section{Calculation of Equilibrium Composition}

The calculation of the equilibrium composition concerns plasma formed of vapor of copper, water vapor and air. The air is constituted of the oxygen atom $(\mathrm{O})$ and nitrogen $(\mathrm{N})$. The water vapor is constituted of the oxygen atom $(\mathrm{O})$ and the hydrogen atom $(\mathrm{H})$ and we are the copper $(\mathrm{Cu})$. This kind of plasmas may be represented by the formula $\mathrm{N}_{\mathrm{x}} \mathrm{O}_{\mathrm{y}} \mathrm{H}_{\mathrm{z}} \mathrm{Cu}_{\mathrm{t}}$, where $\mathrm{x}, \mathrm{y}, \mathrm{z}$ and $\mathrm{t}$ are integer or fractional variables which indicate respectively the number of initial atoms of $\mathrm{H}, \mathrm{O}, \mathrm{N}$ and $\mathrm{Cu}$. These variables are functions of the initial proportions of copper, water vapor and air in the plasma. We tank into account in our calculation fifty five (55) following chemical species:

1. the electrons: $\mathrm{e}^{-}$;

2. the monatomic species (18): $\mathrm{H}, \mathrm{H}^{-}, \mathrm{H}^{+}, \mathrm{N}, \mathrm{N}^{-}, \mathrm{N}^{+}, \mathrm{N}^{++}$, $\mathrm{N}+++, \mathrm{O}, \mathrm{O}^{-}, \mathrm{O}^{+}, \mathrm{O}^{++}, \mathrm{O}+++, \mathrm{Cu}, \mathrm{Cu}^{-}, \mathrm{Cu}+, \mathrm{Cu}++$, $\mathrm{Cu}+++$;

3. the diatomic species (20): $\mathrm{H}_{2}, \mathrm{H}_{2}^{-}, \mathrm{H}_{2}{ }^{+}, \mathrm{N}_{2}, \mathrm{~N}_{2}^{-}, \mathrm{N}_{2}{ }^{+}$, $\mathrm{NH}, \mathrm{NH}^{-}, \mathrm{NH}^{+}, \mathrm{NO}, \mathrm{NO}^{-}, \mathrm{NO}^{+}, \mathrm{O}_{2}, \mathrm{O}_{2}^{-}, \mathrm{O}_{2}{ }^{+}, \mathrm{OH}, \mathrm{OH}^{-}$, $\mathrm{OH}^{+}, \mathrm{CuO}, \mathrm{Cu}_{2}$;

4. the polyatomic species (16): $\mathrm{H}_{2} \mathrm{O}^{+}, \mathrm{N}_{3}, \mathrm{O}_{3}, \mathrm{CuO}, \mathrm{H}_{2} \mathrm{O}$, $\mathrm{N}_{2} \mathrm{O}, \mathrm{NO}_{2}, \mathrm{NH}_{2}, \mathrm{NH}_{3}, \mathrm{~N}_{2} \mathrm{O}_{3}, \mathrm{HNO}_{2}, \mathrm{HO}_{2}, \mathrm{~N}_{2} \mathrm{O}_{4}, \mathrm{H}_{2} \mathrm{~N}_{2}$, $\mathrm{N}_{2} \mathrm{O}_{5}, \mathrm{HNO}_{3}$.

\subsection{Determination of Chemical Composition}

We use the minimization of Gibbs free energy to determine the composition versus the temperature at atmospheric pressure of the considered plasmas [8-20].

At temperature $\mathrm{T}$ and pressure $\mathrm{P}$ the Gibbs free energy is written as [8]:

$$
G=\sum_{i=1}^{N} n_{i}\left(\mu_{i}^{0}+R T_{i} \ln \left(\frac{n_{i}}{\sum_{j=1}^{N} n_{i}}\right)+R T_{i} \ln \left(\frac{P}{P^{0}}\right)\right)
$$

where $n_{i}$ is the mole number of chemical species, $\mathrm{N}$ is the number of different chemical species presented in the plasma and gas, $\mu_{i}{ }_{i}^{0}$ is the chemical potential of $i \quad$ species at standard pressure $\mathrm{P}^{0}\left(10^{5} \mathrm{P}_{\mathrm{a}}\right), \mathrm{R}$ is the molar gas constant. $\mathrm{T}_{\mathrm{i}}$ is the temperature of each chemical species $i$ and is equal to the Temperature $\mathrm{T}$ in the considered case since we assume thermal equilibrium.

\subsection{Numerical Method}

The mole number must be non-negative and satisfy the conservation of nuclei and electrical neutrality, so the different values must satisfy both conditions [8]:

$$
\left\{\begin{array}{l}
n_{i} \geq 0 \quad \forall i \\
\sum_{i=1}^{N} a_{i j} n_{i}=b_{j} \quad j=0, \cdots, m
\end{array}\right.
$$

By introducing the Lagrange multipliers $\pi_{k}$ and using a Newton-Raphson numerical method, the following system can be obtained [8-19]:

$$
\left(\begin{array}{cccccc}
\frac{R T}{n_{1}} & \ldots & 0 & a_{1,0} & \ldots & a_{1,4} \\
\ldots & \ldots & \ldots & \ldots & \ldots & \ldots \\
0 & \ldots & \frac{R T}{n_{M}} & a_{M, 0} & \ldots & a_{M, 4} \\
a_{1,0} & \ldots & a_{M, 0} & 0 & \ldots & 0 \\
\ldots & \ldots & \ldots & \ldots & \ldots & \ldots \\
a_{1,4} & \ldots & a_{M, 4} & 0 & \ldots & 0
\end{array}\right)\left(\begin{array}{c}
\Delta \eta_{1} \\
. . \\
\Delta \eta_{M} \\
\Delta \tau_{0} \\
\ldots \\
\Delta \pi_{4}
\end{array}\right)=\left(\begin{array}{c}
-\mu_{1}^{0}-R T \ln \frac{n_{1}}{\sum_{n_{i}}^{M}}-R T \ln \frac{P}{P^{0}}-\sum_{j=0}^{4} \pi_{j} a_{i, j} \\
\ldots \\
-\mu_{M}^{0}-R T \ln \frac{n_{M}}{\sum^{M} n_{i}}-R T \ln \frac{P}{P^{0}}-\sum_{j=0}^{4} \pi_{j} a_{i, j} \\
-\sum_{i=1}^{M} \pi_{j} a_{i, 1}+b_{1} \\
\ldots \\
-\sum_{i=1}^{M} \pi_{j} a_{i, 4}+b_{4}
\end{array}\right)
$$

The dimension of this linear system is $\mathrm{N}+5$. The coefficients $b_{j}$ depend on the initial volume percentages in the mixture. We calculate the chemical potential of each particle by the data obtained in the works of F. Bendjebbar and al. and using the formula [17]:

$$
\mu_{i}=h_{i}-T s_{i}+E_{i}
$$

Where $h_{i}$ is the specific enthalpy, $S_{i}$ is the specific entropy and $E_{i}$ is the formation enthalpy of the chemical species.

For the polyatomic molecules their data are obtained in the JANAF tables [21]. The chemical potential of each particle 
can be determined by the partition function [22].

Then the values of new molar number and the Lagrangian multipliers are calculated with:

$$
\begin{cases}n_{i}=n_{i}+\lambda \Delta n_{i} & \forall i \in[1, N] \\ \pi_{j}=\pi_{j}+\lambda \Delta \pi_{j} & \forall j \in[0,3]\end{cases}
$$

The parameter $\lambda$ is the highest value included between zero and one that satisfies the following conditions:

$$
n_{i}=n_{i}+\lambda \Delta n_{i} \succ 0 \quad \forall i \in[1, N]
$$

This step avoids obtaining of negative new mole number that appears when they are far from the solution.

The new values of the molar number and Lagrangian multipliers are used for a new calculation cycle. The convergence is considered to be reached when the values $\Delta n_{i}$ satisfy the following relation:

$$
\frac{\Delta n_{i}}{n_{i}} \prec 10^{-15} \quad \forall i \in[1, N]
$$

In the case of our study we take into account 55 chemical species, so $\mathrm{N}=55$.

\section{Results and Analyses}

We present in this section the results of calculations of equilibrium composition at atmospheric pressure of plasmas formed: $90 \%$ air- $5 \%$ water vapor- $5 \% \mathrm{Cu}$ and $80 \%$ air-5\% water vapor-10\% $\mathrm{Cu}$, also we show the influence of the percentage of copper on some major chemical species: $\mathrm{e}^{-}, \mathrm{H}$,
$\mathrm{H}^{+}, \mathrm{N}, \mathrm{N}^{+}, \mathrm{O}, \mathrm{O}^{+}, \mathrm{NO}, \mathrm{NO}^{+}, \mathrm{Cu}_{2}, \mathrm{Cu}, \mathrm{Cu}^{+}, \mathrm{H}_{2} \mathrm{O}, \mathrm{CuO}, \mathrm{CuOH}$, $\mathrm{OH}$ and $\mathrm{OH}^{+}$.

\subsection{Composition of Mixtures Plasmas of Air, Water Vapor and Cooper}

In the figures 1 and 2 , we represent respectively the concentration of chemical species versus temperature at atmospheric pressure and local thermodynamic equilibrium (LTE) of the plasmas formed of $90 \%$ air- $5 \%$ water vapor $-5 \%$ copper and of $80 \%$ air- $5 \%$ water vapor $10 \%$ Copper. On these figures, we can see three (3) phases. The first phase concerns temperature less than $2000 \mathrm{~K}$ ( T $<2000 \mathrm{~K}$ ). In this domain, the main chemical species are molecules: $\mathrm{N}_{2}, \mathrm{O}_{2}, \mathrm{H}_{2} \mathrm{O}, \mathrm{Cu}_{2}$ and $\mathrm{CuOH}$. The second phase concerns the temperature range of $2000 \mathrm{~K}$ to $10000 \mathrm{~K}$ $(2000 \mathrm{~K}<\mathrm{T}<10000 \mathrm{~K})$. In this interval, the main chemical species are: $\mathrm{N}_{2}, \mathrm{O}_{2}, \mathrm{Cu}, \mathrm{NO}, \mathrm{OH}, \mathrm{H}_{2}, \mathrm{~N}, \mathrm{O}, \mathrm{H}$ $\mathrm{Cu}^{+}$and $\mathrm{e}^{-}$. The third phase concerns temperature above $10000 \mathrm{~K}(\mathrm{~T}>10000 \mathrm{~K})$. In this range, the main chemical species are: $\mathrm{N}, \mathrm{O}, \mathrm{H}, \mathrm{H}^{+}, \mathrm{O}^{+}, \mathrm{N}^{+}$and $\mathrm{e}^{-}$. The analyses of the curves show that the numerical density of the neutral particles $\mathrm{H}, \mathrm{O}, \mathrm{N}$ and $\mathrm{Cu}$ depend of the percentage of the initial mixture. The electrical conductivity is directly linked to the electronic density of the medium. In low temperatures $(\mathrm{T}<12000 \mathrm{~K})$ the electrical neutrality is made mainly between $\mathrm{e}^{-}$and $\mathrm{Cu}^{+}$because the ionization energy of the particle $\mathrm{Cu}$ is low than those of $\mathrm{N}, \mathrm{H}$ and $\mathrm{O}$. We can therefore note that the numerical densities of the copper atoms will have a considerable influence on the properties of the plasma formed for temperatures below $10000 \mathrm{~K}$.

\section{Plasma 90\% Air-5\% Water vapor-5\% Copper}

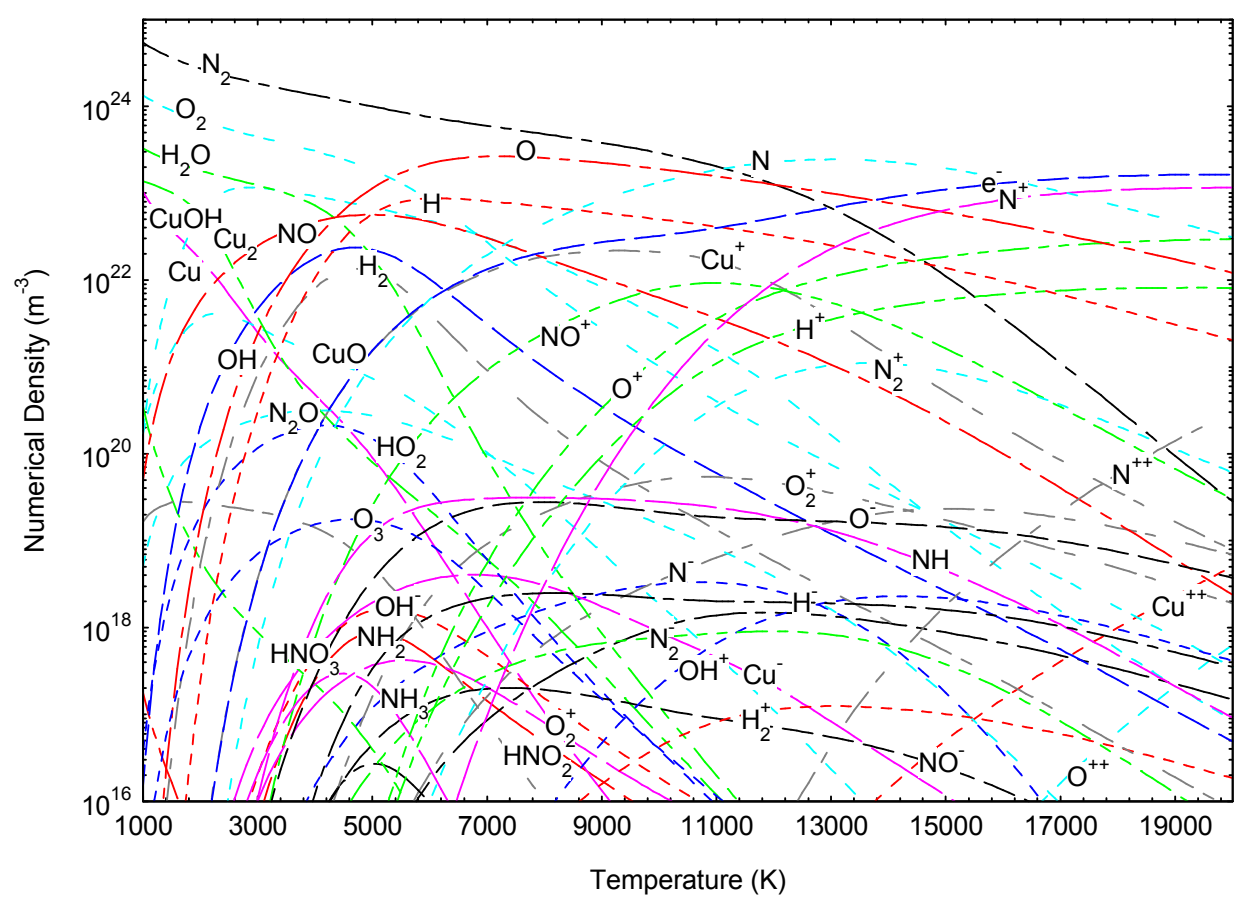

Figure 1. Evolution of numerical densities versus temperature of plasma formed of mixture $90 \%$ Air-5\%Water vapor-5\%Copper. 
Plasma $85 \%$ Air-5\% Water vapor-10\% Copper

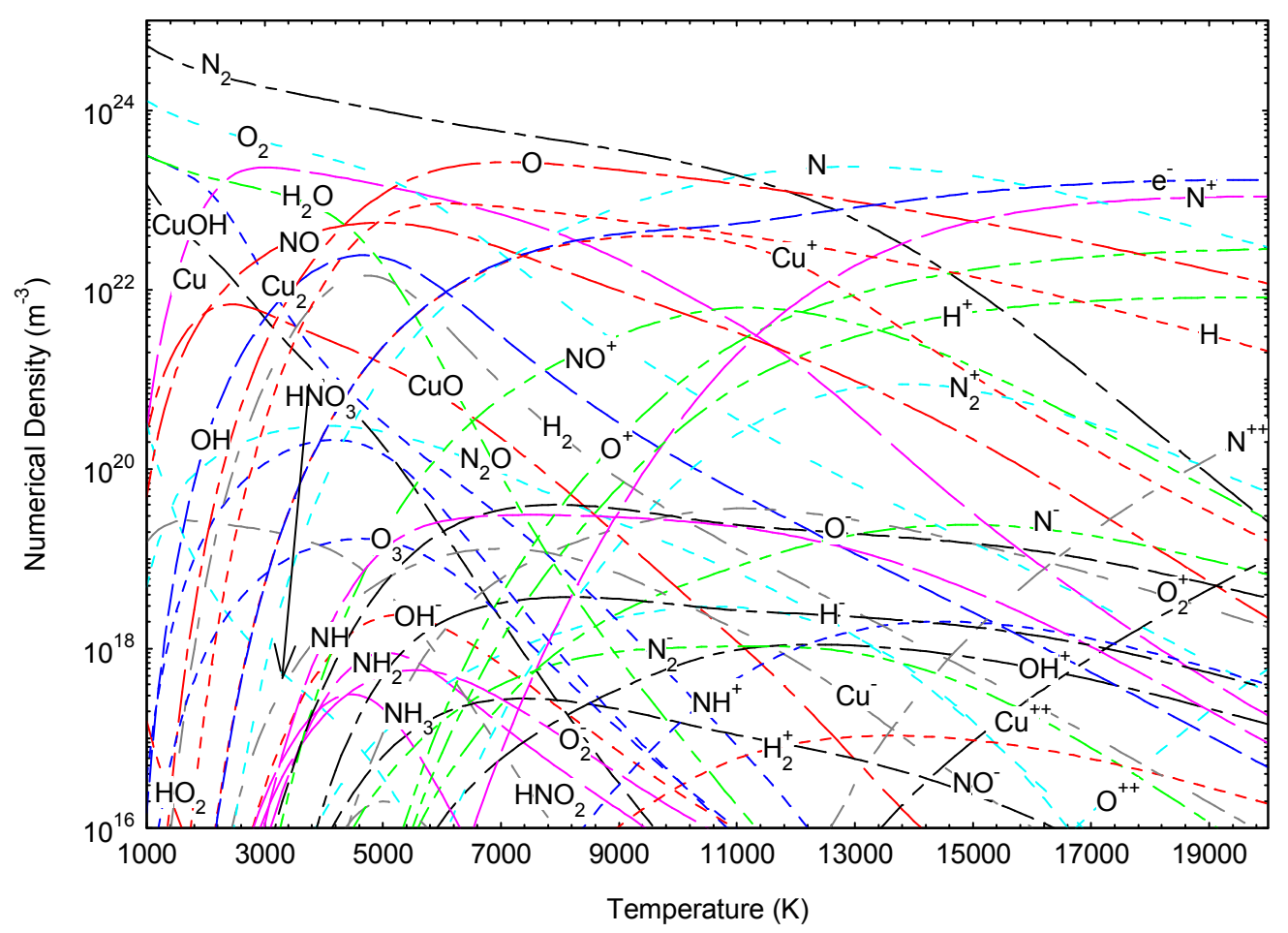

Figure 2. Evolution of numerical densities versus temperature of plasma formed of mixture $85 \%$ Air-5\%Water vapor-10\%Copper.

For high temperature $(\mathrm{T}>12000 \mathrm{~K})$, the ionization of the atoms $\mathrm{H}, \mathrm{O}$ and $\mathrm{N}$ take place to the production of electrons and the electrical neutrality is made mainly between $\mathrm{e}^{-}, \mathrm{N}^{+}$, $\mathrm{O}^{+}$and $\mathrm{H}^{+}$. We remark that in this range of temperature ionization of $\mathrm{N}$ to $\mathrm{N}^{+}$contributes most to electrons production. The copper molecule $\mathrm{Cu}_{2}$ dissociates around $1500 \mathrm{~K}$. The water molecule $\mathrm{H}_{2} \mathrm{O}$ dissociates around 3800 $\mathrm{K}, \mathrm{O}_{2}, \mathrm{H}_{2}, \mathrm{NO}$ and $\mathrm{OH}$ molecules dissociate around $5000 \mathrm{~K}$. The diazote molecule $\mathrm{N}_{2}$ dissociate around $9000 \mathrm{~K}$. On these figures, we note that the polyatomic species: $\mathrm{O}_{3}, \mathrm{H}_{2} \mathrm{O}$, $\mathrm{CuO}, \mathrm{N}_{2} \mathrm{O}, \mathrm{NH}_{3}, \mathrm{~N}_{2} \mathrm{O}_{3}, \mathrm{HNO}_{2}, \mathrm{HO}_{2}, \mathrm{~N}_{2} \mathrm{O}_{4}, \mathrm{H}_{2} \mathrm{~N}_{2}, \mathrm{~N}_{2} \mathrm{O}_{5}$ and $\mathrm{HNO}_{3}$ appear only in very low temperature and their concentrations are often very low These particles are low energies of dissociation. These particles disappear rapidly with temperature because their dissociation energies are low. The electronegative chemical species namely: $\mathrm{H}^{-}, \mathrm{Cu}^{-}$, $\mathrm{O}^{-}, \mathrm{OH}^{-}, \mathrm{NO}^{-}, \mathrm{O}_{2}^{-}, \mathrm{N}_{2}^{-}$and $\mathrm{H}_{2}^{-}$species appear with low concentration. However, these particles could have a significant influence on the electrical conductivity of the plasma, because they capture electrons and decrease their mobility in the plasma.

\subsection{Influence of the Percentage of Copper on the Equilibrium Composition}

To estimate the effect of the percentage of metallic vapor of copper on the equilibrium composition, we have shown in Figures 3 and 4 the numerical densities of the majority chemical species. We have varied the percentage of metallic copper vapor as $1 \%, 2 \%, 3 \%, 4 \%, 5 \%$ and $10 \%$ in the mixture. The direction of the arrows indicates the increasing direction of the percentages of copper. The evolution of the curves shows that the numerical density of the chemical species $\mathrm{N}_{2}, \mathrm{O}_{2}, \mathrm{H}_{2} \mathrm{O}, \mathrm{NO}, \mathrm{H}_{2}, \mathrm{O}, \mathrm{N}$ and $\mathrm{H}$ vary very little when the percentage of copper increases in the mixture. We note that on the others hand the numerical densities of the chemical species $\mathrm{NO}^{+}, \mathrm{CuO}, \mathrm{Cu}_{2}, \mathrm{OH}^{+}$, $\mathrm{CuOH}, \mathrm{Cu}$, e- and $\mathrm{Cu}^{+}$increase when the percentage of copper increases in the medium. The chemical species containing the copper atom increase more with the percentage of metallic copper vapor. We also note that the numerical densities of the $\mathrm{N}^{+}, \mathrm{O}^{+}$and $\mathrm{H}^{+}$particles decrease when the percentage of copper increases in the plasma. In particular, the electron density increases with the percentage of copper. This is due to the fact that electroneutrality is mainly made between the electrons and the $\mathrm{Cu}^{+}$ion for temperatures below $12,000 \mathrm{~K}$. At high temperatures $(\mathrm{T}>17,000 \mathrm{~K})$ the electron density is independent of the copper vapor rate. This is explained by the fact that the plasma tends to be fully ionized, so it does not depend on the type of plasma. The electrical conductivity is directly linked to the electronic density, the shape of the electronic density shows that the electrical conductivity will increase with the copper content, especially for temperatures below $12000 \mathrm{~K}$. As the minimization of the electrical conductivity is desired in the circuit breakers for breaking the electric arc, significant evaporation of the copper contacts will reduce the performance of the circuit breaker for breaking the electric arc. 


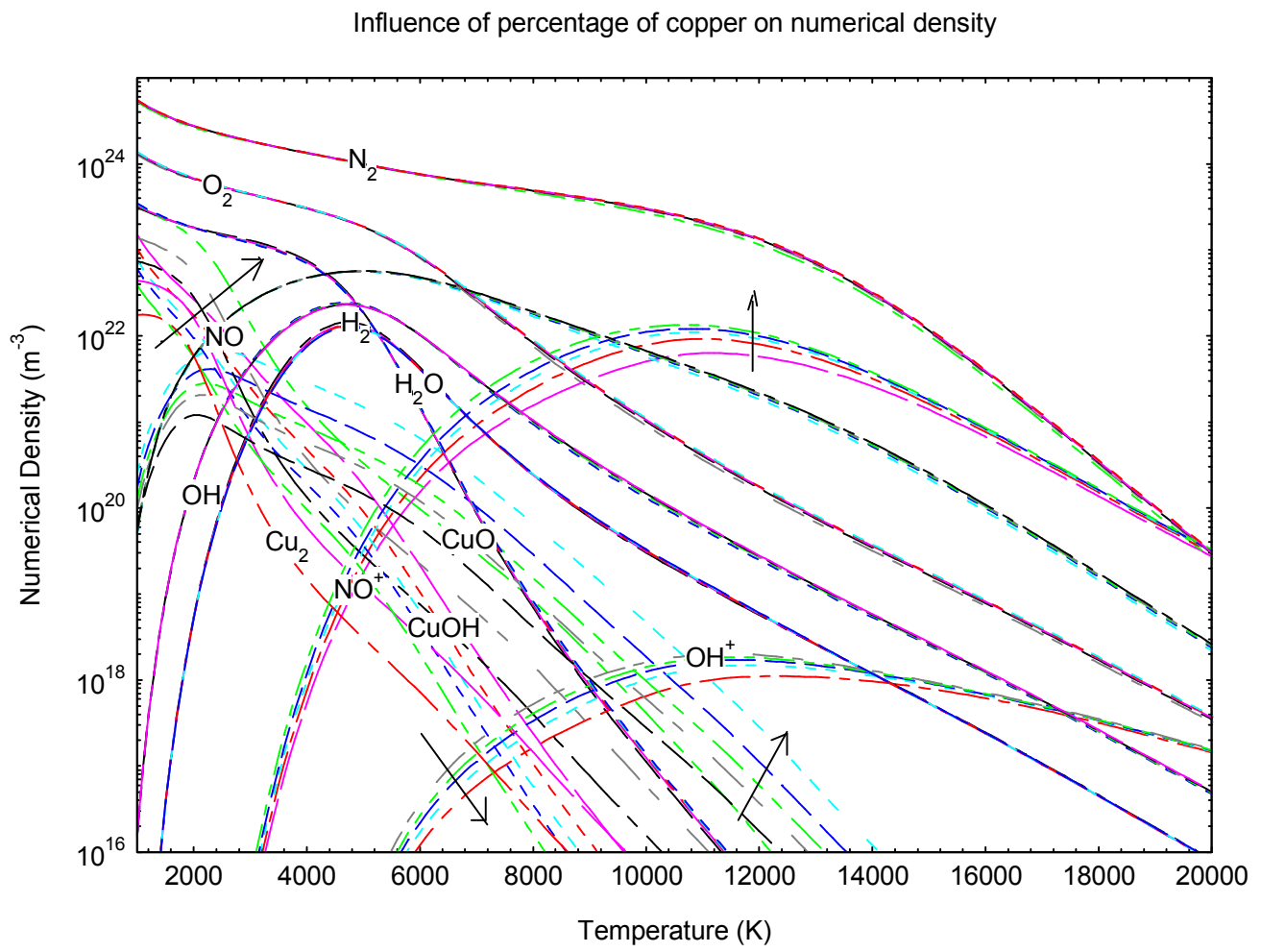

Figure 3. Influence of the percentage of metallic copper vapor on numerical densities versus temperature of majority chemical species in the plasma.

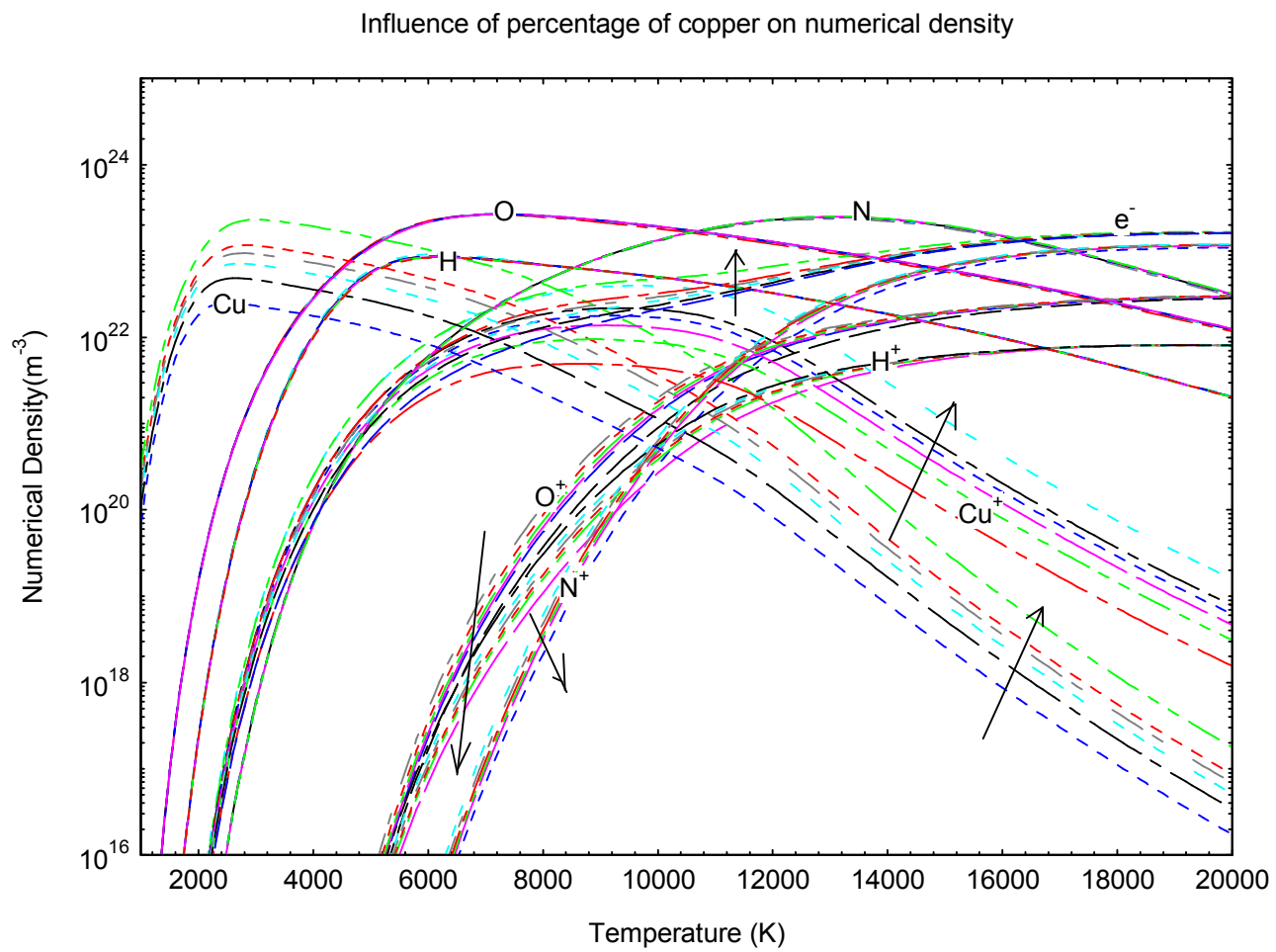

Figure 4. Influence of the percentage of metallic copper vapor on numerical densities versus temperature of majority chemical species in the plasma.

\subsection{Influence of the Pressure on the Equilibrium Composition}

To appeciate the influence of pressure on the plasma equilibrium composition of the mixture, we have presented in figures 6 and 7, the evolution in function of temperature the numerical densities of the main chemical species in the plasma formed by $90 \%$ Air-5\% Water vapor and $5 \%$ copper vapor. We have retained four (4) values of pressure: $\mathrm{P}=1$ atm, $\mathrm{P}=5 \mathrm{~atm}, \mathrm{P}=10 \mathrm{~atm}$ and $\mathrm{P}=15 \mathrm{~atm}$. In each figure, the arrows indicate the increasing direction of the pressure. 
The numerical densities of all chemical species increases if the pressure increases in the plasma. This is explained by Dalton's Law or the Law of perfect gases $(\mathrm{P}=\mathrm{nkT})$. The average energy per particle will therefore decreases. As the dissociation and ionization reactions are endothermic, chemical reactions occur hardly in the plasma. Indeed, at a fixed temperature, when the pressure increases, chemical density must be increases to verify the law of Dalton.

Generally, the increasing of the pressure retard chemical reactions because it disadvantages the dislocations that constitute dissociation and ionization reactions in the plasma. It can therefore be said that dissociation and ionization reactions occur at high temperature if the pressure increases in the plasma.

Influence of pressure on numerical density of chemical species

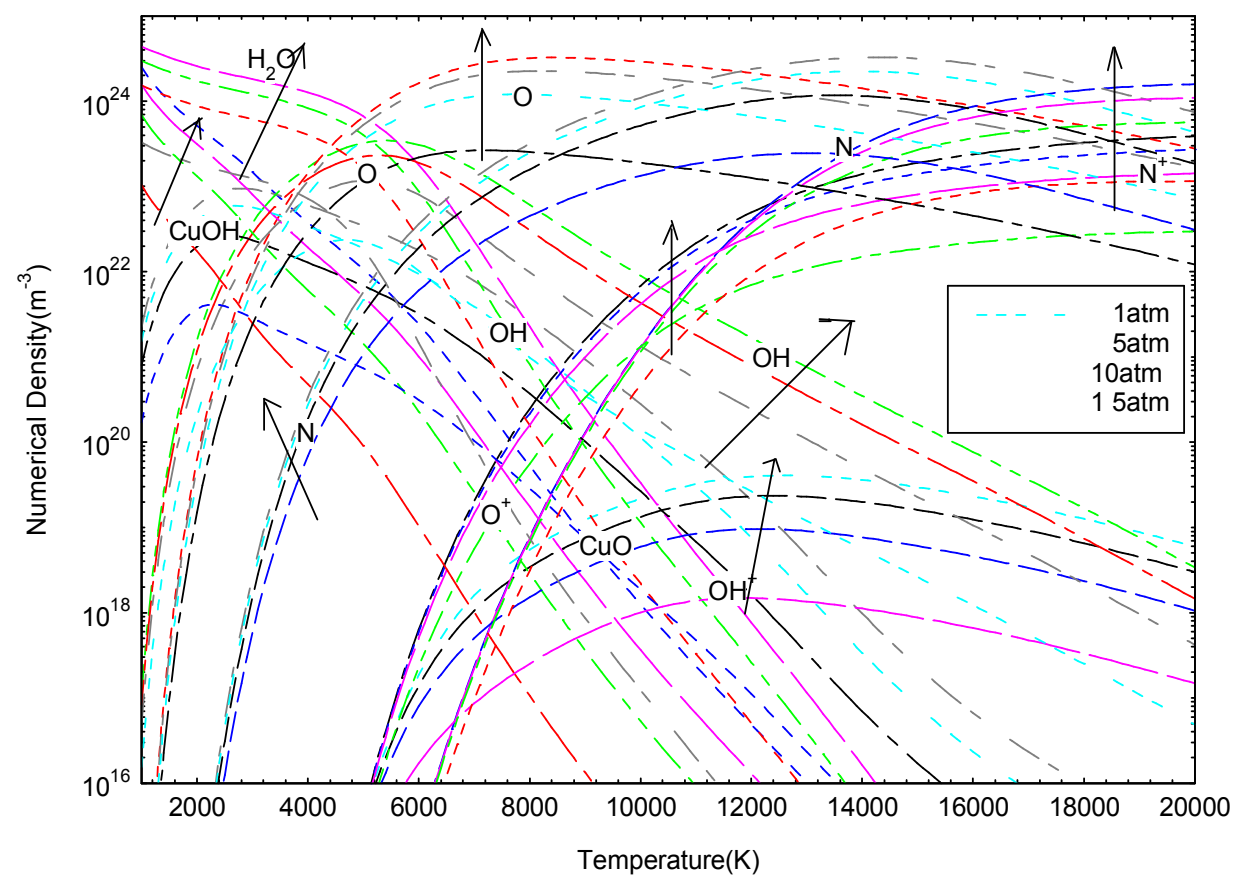

Figure 5. Influence of the pressure on numerical densities versus temperature of majority chemical species in the plasma $\left(\mathrm{H}_{2} \mathrm{O} ; \mathrm{CuOH} ; \mathrm{O}\right.$; $\mathrm{CuO}$; $\mathrm{OH}$; $\mathrm{O}^{+}$; $\left.N^{+} ; N\right)$.

Influence of pressure on numerical density of chemical species

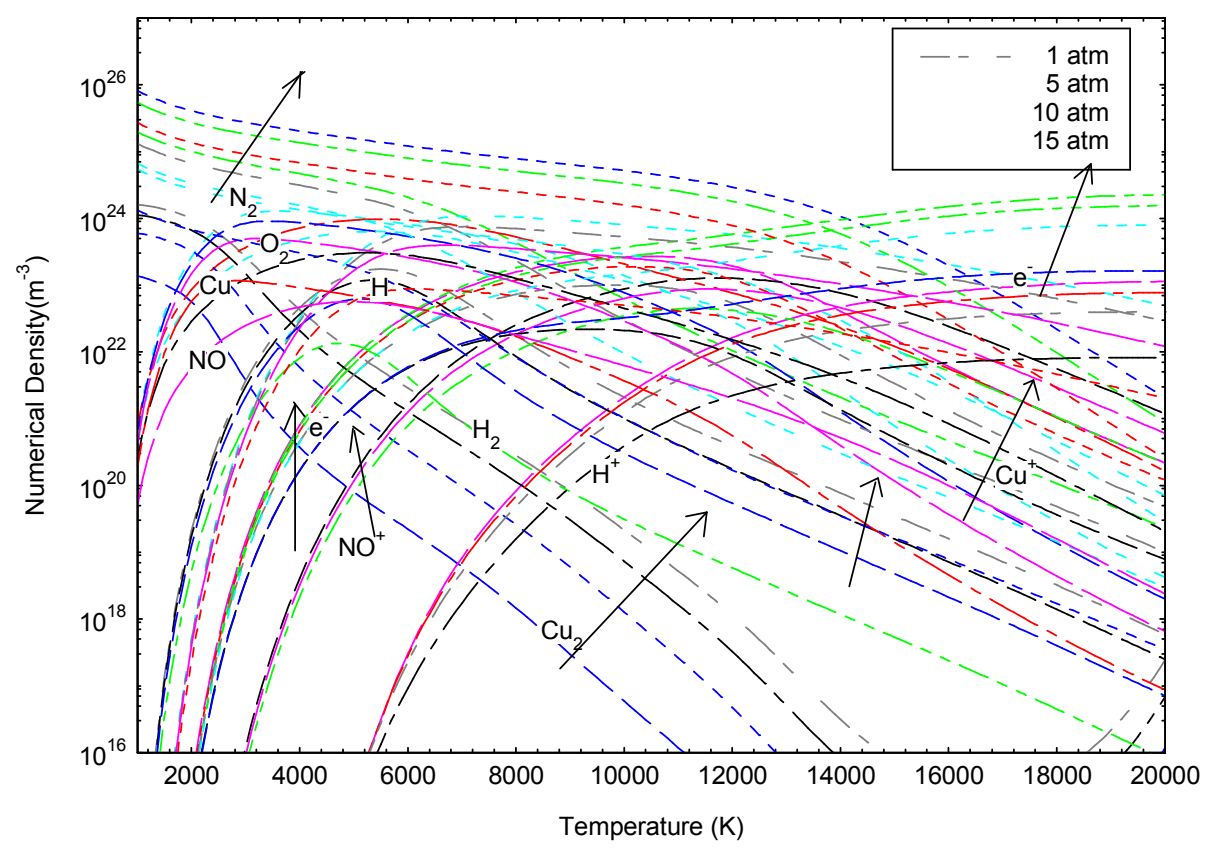

Figure 6. Influence of the pressure on numerical densities versus temperature of majority chemical species in the plasma $\left(e^{-} ; \mathrm{O}_{2} ; \mathrm{Cu}^{2} \mathrm{H}^{+} ; \mathrm{Cu}^{+} ; \mathrm{H}_{2} ; \mathrm{Cu}_{2} ; \mathrm{NO}\right.$; $\mathrm{N}_{2} ; \mathrm{H} ; \mathrm{NO}^{+}$). 


\section{Conclusion}

The calculation of the numerical densities versus temperature have shown the influence of the copper vapors coming from the contacts of the circuit breakers on the chemical composition of the plasma of mixture of air and water vapor. The study showed that in general the numerical densities of chemical species containing the copper atom increase with the addition of copper to the medium. Electroneutrality is mainly made between the electrons and the $\mathrm{Cu}^{+}$copper ion for temperatures below $12000 \mathrm{~K}$. The electron density increases with the percentage of copper for temperatures below $17000 \mathrm{~K}$. The result are also shown that the increasing of pressure on the plasma induce the increasing of the chimical density and retard the chemical reactions. The electrical conductivity is directly linked to the electronic density, the behavior of the electronic density shows that the electrical conductivity will increase with the copper content in the plasma, especially for temperatures below $17000 \mathrm{~K}$. As a minimum electrical conductivity is desired in the circuit breakers for breaking the electric arc, significant evaporation of the copper contacts could reduce the performance of the circuit breaker for breaking the electric current. However, the equilibrium composition calculations alone do not make it possible to highlight the role of copper vapor on the interruption of the electric current. The calculations of the transport coefficients, and more particularly the thermal conductivity could highlight it. There is also the dynamic viscosity of the plasma that you need to get an idea of the speed of movement of the electric arc.

\section{References}

[1] P. André, M. A. Courty, A. K. Kagoné, Z. Koalaga, N. Kohio, F. Zougmoré: Calcul de la composition chimique dans un plasma issu de mélanges de PTFE, d'air, de cuivre et de vapeur d'eau dans le cadre d'appareillages de coupure électrique à air Journal International de Technologie, de l'Innovation, de la Physique, de l'Energie et de l'Environnement. vol. 2, $\mathrm{n}^{\circ} 1, \quad 3$, (2016) DOI: http://dx.doi.org/10.18145/jitipee.v2i1.128.g70.

[2] Abdoul Karim Kagoné, Zacharie Koalaga et François Zougmoré: Calcul de composition de plasmas thermiques d'arc électrique de mélanges d'air et de vapeur d'eau. Rev. can. phys. 90: 211-221 (2012) doi: 10.1139/P2012-004.

[3] Pascal André, Abdoul Karim Kagoné, Zackarie Koalaga, Nièssan Kohio et François Zougmoré. Contribution à l'étude de la conductivité thermique d'un plasma d'air. Journal International de Technologie, de l'Innovation, de la Physique, de l'Energie et de l'Environnement. (2019) DOI: http://dx.doi.org/10.18145/jitipee.v5i2.222

[4] Yi Wu, Zhexin Chen, Fei yang, Yann Cressault, Anthony B Murphy, Anxiang Guo, Zirui Liu, Mingzhe Rongand Hao Sun: Two-temperature thermodynamic and transport properties of $\mathrm{SF}_{6}-\mathrm{Cu}$ plasmas J. Phys. D: Appl. Phys. 48 (2015) 415205 (25pp) doi: 10.1088/0022-3727/48/41/415205.

[5] KOHIO Niéssan, KAGONÉ Abdoul Karim, KOALAGA Zacharie, ZOUGMORÉ François Composition of Air-Water Vapor Mixtures at Low Temperatures. International Journal of
Advanced Research in Science Engineering and Technology. Vol. 1, Issue 5, December (2014).

[6] Kohio Nièssan, Kagoné Abdoul Karim, Yaguibou Wêpari Charles, Koalaga Zacharie, Zougmoré François: Water Vapor Influence on Thermodynamic Properties of Air-water Vapor Mixtures Plasmas at Low Temperatures: International Journal of Physics, (2019), Vol. 7, No. 3, 66-72 DOI: 10.12691/ijp-7-3-1.

[7] P. André and Z. Koalaga, "Composition of a thermal plasma formed from PTFE with copper in non-oxidant atmosphere. Part II: Comparison of a test case with nitrogen", High Temperature Material Processes 14, 3 (2010) 289.

[8] Weizong Wang Mingzhe Rong Yi Wu. Transport Coefficients of High Temperature SF6-He Mixtures Used in Switching Applications as an Alternative to Pure SF6. Plasma Chem Plasma Process (2014). DOI: 10.1007/s11090-014-9543-3.

[9] Wêpari Charles Yaguibou, Niessan Kohio, Abdoul Karim Kagone and Zacharie Koalaga: Impact of Aerosol on Transport Coefficients of Air Thermal Plasmas in Circuit Breakers. (2018) Volume No. 7, Issue No. 4, pp: 43-47. DOI: 10.5958/2319-6890.2018.00094.6.

[10] P. André, J. Aubreton, S. Clain, M. Dudeck, E. Duffour, M. F. Elchinger, B. Izrar, D. Rochette, R. Touzani and D. Vacher. Transport coefficients in thermal plasma. Applications to Mars and Titan atmospheres. Eur. Phys. J. D 57, 227-234 (2010). DOI: $10.1140 /$ epjd/e2010-00036-5.

[11] D. Rochette, W. Bussière and P. André. Composition enthalpy and Vaporisation temperature calculation of $\mathrm{Ag}-\mathrm{SiO}_{2}$ plasma with air in the temperature range from $1000 \mathrm{~K}$ to $6000 \mathrm{~K}$ and for pressure included between 150 bars. Plasma chemistry and plasma processing, Vol. 24, No. 3, Septembre (2004).

[12] H. Hingana. Contribution à l'étude des propriétés des plasmas a deux températures: application à l'argon et l'air. Thèse de doctorat, Université Toulouse III-Paul Sabatier (France), Décembre (2010).

[13] Wêpari Charles Yaguibou, Nièssan Kohio, Abdoul Karim Kagoné, Zacharie Koalaga et François Zougmoré: Influence des aérosols sur la composition à l'équilibre d'un plasma d'air vol. $4, \quad$ (2018) DOI: http://dx.doi.org/10.18145/jitipee.v4i1.167.

[14] N. KOHIO, A. K. KAGONÉ, Z. KOALAGA, F. ZOUGMORÉ. Composition of Air -Water Vapor Mixtures at Low Temperatures (2014). International Journal of Advanced Research in Science, Engineering and Technology. Vol. 1, Issue 5.

[15] P. André, L. Brunet, W. Bussière, J. Caillard, J. M. Lombard, and J. P. Picard. Transport coefficients of plasmas consisting of insulator vapours. Application to PE, POM, PMMA PA66 and PC. Eur. Phys. J. Appl. Phys. 25, 169-182 (2004). DOI: 10.1051/epjap: 2004007.

[16] P. André, J. Aubreton, S. Clain, M. Dudeck, E. Duffour, M. F. Elchinger, B. Izrar, D. Rochette, R. Touzani and D. Vacher. Transport coefficients in thermal plasma. Applications to Mars and Titan atmospheres (2010). Eur. Phys. J. D 57, 227-234. DOI: $10.1140 /$ epjd/e2010-00036-5.

[17] Yulianta Siregar, Yasunori Tanaka, Yoshihiko Uesugi, Tatsuo Ishijima: Numérical parametric Investigationon the Temperature Distribution in $\mathrm{Ar} / \mathrm{O}_{2}$ Induction Thermal Plasma the Ti power Injection: Inclusion of Particule Evaporation; IEEJ Trans (2020); 15: 12-2 DOI: 10.1002/tee.23022. 
[18] F. Bendjebbar, P. Andre, M. Bnebakkar, D. Rochette, S. Flazi, D. Vacher. Plasma Formed in Argon, Acid Nitric and Water Used in Industrial ICP Torches. Plasma Sciences and Technology, Vol. 14, No. 8, Aug. (2012).

[19] Z Koalaga. Composition d'équilibre des plasmas de $\mathrm{H}_{2}, \mathrm{O}_{2}$ et $\mathrm{N}_{2}$ hors équilibre thermique. Canadian Journal of Physics (2003). https://doi.org/10.1139/p03-075.

[20] Yi Wu, Chunlin Wang, Hao Sun, Anthony B Murphy, Mingzhe Rong, Fei Yang, Zhexin Chen, Chunpin Niuand Xiaohua Wang: Properties of $\mathrm{C}_{4} \mathrm{~F}_{7} \mathrm{~N}-\mathrm{CO}_{2}$ thermal plasmas: thermodynamic properties, transport coefficients and emission coefficients J. Phys. D: Appl. Phys. 51, (2018).

[21] M. W Chase. JR, C. A. Davies. JR Downey, JR. DJ. Frurip, R. A, Mcdanold, A. N. Syverud. Janat thermodynamic table third edition. J. Phys and Chem. Ref. Data. Vol. 14; 1985.

[22] Yann CRESSAULT propriétés des plasmas thermiques dans des mélanges argon-hydrogène-cuivre. Thèse de doctorat UNIVERSITE PAUL SABATIER TOULOUSE III. novembre (2001). 